\title{
Prehospital Emergency Medicine at the Beach: What Is the Effect of Fins and Rescue Tubes in Lifesaving and Cardiopulmonary Resuscitation After Rescue?
}

\author{
Cristian Abelairas-Gómez, $\mathrm{PhD}$; Roberto Barcala-Furelos, $\mathrm{PhD}$; Marcos Mecías-Calvo, $\mathrm{PhD}$; \\ Ezequiel Rey-Eiras, PhD; Sergio López-García, PhD; Javier Costas-Veiga, PE; Antonio Bores-Cerezal, PhD; \\ Jose Palacios-Aguilar, $\mathrm{PhD}$ \\ From the School of Nursing, CLINURSID Network Research, Universidade de Santiago de Compostela, Santiago de Compostela, Spain \\ (Drs Abelairas-Gómez and Barcala-Furelos); the Faculty of Health Sciences, European Atlantic University, Santander, Spain \\ (Drs Abelairas-Gómez and Mecías-Calvo, Mr Costas-Veiga, and Dr Bores-Cerezal); the Faculty of Education and Sport Sciences, \\ University of Vigo, Pontevedra, Spain (Drs Barcala-Furelos and Rey-Eiras, and Mr Costas-Veiga); the IDRA, International Drowning \\ Research Alliance, Rio de Janeiro, Brazil (Dr Barcala-Furelos); Faculty of Education, Pontifical University of Salamanca, Salamanca, \\ Spain (Dr López-García); and the Faculty of Sport Sciences and Physical Education, University of A Coruña, A Coruña, Spain \\ (Dr Palacios-Aguilar).
}

Objective.-To analyze the influence of fins and rescue tube use in a water rescue, assessed by time and distance to salvage position, physiological parameters, and cardiopulmonary resuscitation (CPR).

Methods.- Twenty professional lifeguards (10 men, 10 women) conducted 3 tests: a baseline test of 5 minutes of CPR and 2 water rescues, 1 without rescue equipment (NRE), and the other with fins and rescue tube (FRT). They also had to perform 5 minutes of CPR after each rescue. Time and distance of the rescues, physiological parameters (blood lactate concentration and heart rate), and quality of CPR were analyzed.

Results. - CPR quality worsened by 26 to $28 \%(P<.001)$ after rescue. However, there were no differences using FRT. The use of rescue equipment reduced the time (FRT: 216 57 seconds; NRE: $319 \pm 127$ seconds; $P<.001$ ) and distance covered (FRT: $265 \pm 52 \mathrm{~m}$; NRE: $326 \pm 41 \mathrm{~m} ; P<.001$ ). No differences were found in lactate levels between FRT and NRE just after the rescues, but there were some after 5 minutes of subsequent CPR (FRT: $10.7 \pm 2.2 \mathrm{mmol} / \mathrm{L}$; NRE: $12.6 \pm 1.8 \mathrm{mmol} / \mathrm{L}$; $P<.001)$. Comparing women with men, we found significant differences in lactate concentrations only in FRT (women: $9.6 \pm 1.4 \mathrm{mmol} / \mathrm{L}$; men: $8.1 \pm 1.2 \mathrm{mmol} / \mathrm{L} ; P=.031$ ).

Conclusions.- The use of fins and rescue tube provides a comprehensive benefit in an aquatic emergency. However, FRT did not have any effect on the quality of the postrescue CPR.

Keywords: water rescue, cardiopulmonary resuscitation, lifesaving equipment, drowning, lifeguard, blood lactate

\section{Introduction}

Lifeguards are professionals responsible for the prevention and rescue of drowning victims. Drowning is considered a public health issue by the World Health Organization (WHO). ${ }^{1}$ Approximately $0.7 \%$ of all the deaths worldwide are due to unintentional drowning. ${ }^{2}$

Corresponding author: Roberto Barcala-Furelos, $\mathrm{PhD}$, Faculty of Education and Sport Sciences, Campus A Xunqueira, s/n, 36005, Pontevedra Spain; e-mail: roberto.barcala@uvigo.es.

Submitted for publication July 2016.

Accepted for publication March 2017.
This means more than 1000 deaths each day all over the world. Alcohol consumption in or around aquatic environments, ${ }^{3,4}$ sex-since males are twice as likely to drown as females, ${ }^{5}$ and self-reported swimming competency $^{6}$ are considered drowning risk factors. Immersion and submersion are 2 different events related to drowning whose precursors are cooling of skin, superficial nerves, muscles in the limbs, and deep body tissues. Hypothermia, aspiration, and swallowing water are determining factors in clinical status. In severe hypothermia, the person will become unconscious quickly, and aspiration and swallowing will cause 
systemic hypoxemia, which is life-threatening. ${ }^{7}$ In this case, the risk of neurological damage is similar to that in other instances of cardiac arrest, so the person should be taken as quickly as possible to dry land. ${ }^{2}$ To prevent the morbidity and mortality from drowning, the rescuer must swim to the victim, provide flotation, prevent further submersion, and get the victim out of the water, as morbidity from drowning may occur in a few minutes and a swift response is vital. ${ }^{2}$

The intervention to rescue a drowning victim requires a specific preparation in special conditions. Lifeguards spend much of their time looking out to sea (surveillance), but with the occasional requirement to move to high-intensity activity and casualty handling in a compressed period of time (aquatic rescue). ${ }^{8}$ In the case of an aquatic rescue, lifeguards have to decide which rescue equipment they should use. It has been suggested that the material that combines propelling and/or floating in equipment makes the rescue of victims safer, faster, and more efficient. ${ }^{9-13}$ This can be obtained with 1 component, for example a surfboard, rescue tube, or torpedo buoy. ${ }^{9}$ Or, through a combination of propulsion fins and a floating device (such as a rescue tube or torpedo buoy). ${ }^{10,11}$ However, evidence regarding which equipment's use is more beneficial is anecdotal, and there is little information on which variables are more advantageous to minimize time of rescuing the victim. ${ }^{12}$

The objective of this research is to compare the use of rescue material against the use of no rescue material for both objective and subjective measures of cardiopulmonary resuscitation (CPR), and to reduce performance and physiologic strain in a manikin-based simulation of a lifeguard water rescue.

\section{Materials and Methods}

\section{SAMPLE}

A convenience sampling was used, and 20 professional lifeguards took part in this study. Participants were recruited by email, and written and oral consent were obtained. Their participation was voluntary and with no remuneration for collaborating. All lifeguards were trained in the European Resuscitation Council Guidelines for Resuscitation (ERCGR 2010). ${ }^{14}$ The project was approved by the Ethics Committee of the Faculty of Education and Sport Sciences of the University of Vigo (Spain).

\section{STUDY DESIGN}

A quasi-experimental design was used in the evaluation of this crossover study. Variables were grouped in 3 objective categories (quality of CPR, rescue performance, and rescuer's physiological load) and 1 subjective category (perception of effort).

Firstly, descriptive information concerning sex, age, weight, height, as well as body mass index (BMI), was recorded. The subjects then carried out 3 tests (Figure 1).

The first test consisted of performing a 5-minute simulated manikin resuscitation according to ERCGR 2010. ${ }^{14}$ Participants were rested at the time of the beginning of this test.

The second and the third test evaluated 2 common lifesaving situations: swimming rescue without auxiliary materials (no rescue equipment [NRE]) and with auxiliary rescue equipment composed of fins and water rescue tube (FRT). The rescues were carried out in 2 consecutive days to avoid the effect of fatigue and provide very similar environmental and sea conditions. In order to prevent learning effect, the order of the lifesaving was randomized for each participant with a random number generator.

\section{CARDIOPULMONARY RESUSCITATION TEST}

Each lifeguard conducted 3 CPR tests: a 5-minute baseline test, and the same test at the end of each rescue (30 compressions: 2 rescue breaths). The test was carried out in the laboratories of the Faculty of Physical Education and Sport Sciences of the University of A Coruña. The second and the third CPR tests were conducted after each rescue at the beach.

Resuscitation parameters were evaluated with Laerdal Resusci Anne manikin (Stavanger, Norway) with the Laerdal PC SkillReporting software 2010 Resuscitation Guidelines. This model records the quality of compressions and rescue breaths, differentiating whether they are correct or not. The manikin checks the depth (correct: 50-60 mm), rate (correct: 100-120 compressions per minute), chest recoil, and hands position. For rescue breaths, a 500 to $600 \mathrm{~mL}$ tidal volume was considered correct. No feedback was permitted during the test, and compressions and rescue breaths were considered correct when there were no errors.

The cardiopulmonary variables were: chest compression rate (CCR) in compression/minutes, quality of chest compression (QCCp) as a percentage, quality of ventilations $(\mathrm{QVp})$ as a percentage, and overall quality resuscitation percentage: $\mathrm{QCPR}=[(\mathrm{QCC}+\mathrm{QVp}) / 2]$.

\section{LIFESAVING TEST}

A standard lifesaving test ${ }^{10,15}$ was carried out consisting of: a 50-meter sand run, starting at the watch tower; a round-trip swim $(75 \mathrm{~m}$ swimming and $75 \mathrm{~m}$ back, towing the manikin: total $150 \mathrm{~m}$ ); and a $10-\mathrm{m}$ victim extraction to dry sand. 


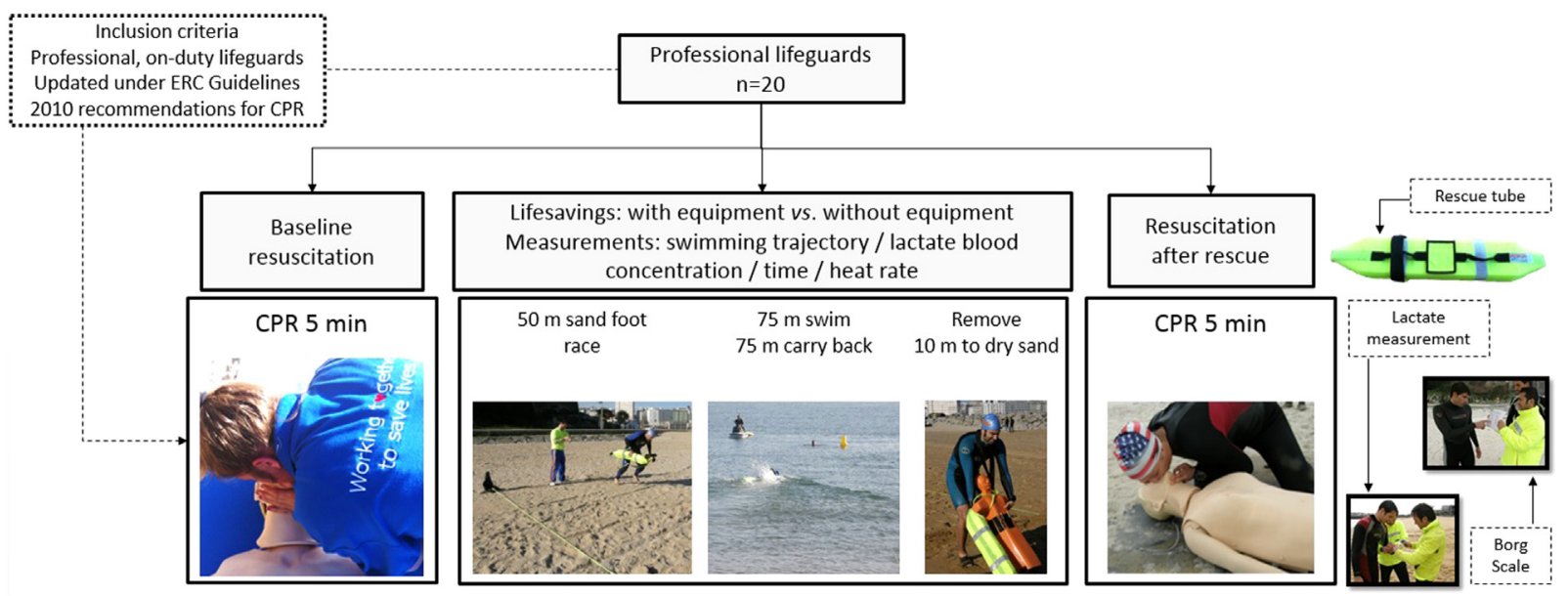

Figure 1. Study design flowchart. Twenty lifeguards performed 3 CPR tests: baseline (after rescue without material; no rescue equipment [NRE] and after rescue with equipment; fins and rescue tube [FRT]), and 2 water rescue tests (NRE and FRT).

A test-approved water rescue manikin was used situated at a 75 -meter distance from the shore. ${ }^{10,15}$ This test takes into account the approximate distance in which most rescues happen, which is the usual average drowning distance. ${ }^{16}$

Each lifeguard was informed that it was an emergency simulation and that they should technically and physically respond in accordance with the situation.

\section{LOCATION AND ENVIRONMENTAL CONDITIONS}

The test was performed at Oza beach (A Coruña, Spain), a beach at the bay with hardly any climatic and maritime changes. It was chosen because it had previously been used in other related lifeguard studies. ${ }^{15}$

Tests were carried out on 2 consecutive days with similar conditions. Waves were between 0 and $0.25 \mathrm{~m}$ ( 0 value according to the Douglas sea scale) on both days, and the water and ambient temperature were 17 to $19^{\circ} \mathrm{C}$ and 21 to $25^{\circ} \mathrm{C}$, respectively. These data were provided by the local meteorological agency.

\section{CHARACTERISTICS OF THE RESCUE MATERIAL}

The lifeguard equipment characteristics were a common rescue tube model $100 \times 16 \times 9 \mathrm{~cm}$ with a capability of buoyancy of $150 \mathrm{~N}$; and rubber fins with a minimum length of 40, and a maximum length of $80 \mathrm{~cm}$. Each lifeguard used his own rubber fins to avoid anatomic foot adaption issues.

\section{RESCUE PERFORMANCE}

The rescue dependent variables were: time of rescue (TR) in seconds, and distance to the rescue (D) in meters.
Swimming trajectory was measured with a Keymaze 700 GPS (Geonaute, France) with acquisition of satellite data every 0.1 seconds and $5 \mathrm{~m}$ in Wide Area Augmented System and European Geostationary Navigation Overlay Service (WAAS/EGNOS) mode of location accuracy. ${ }^{17}$

\section{RESCUE PHYSIOLOGICAL LOAD}

The physiological variables were subjective perception of effort, lactate values, and heart rate. Subjective physiological variables were measured by Borg rating of perceived exertion (RPE) modified scale ${ }^{18}$ taken at the end of the test.

Three lactate levels were measured: baseline lactate level at the beginning of the rescue $(\mathrm{LaB})$, immediately before the test started; lactate level at the end of the rescue (LaR), immediately after the manikin extraction; and lactate level after resuscitation (LaCPR). Three blood samples were collected 1, 3, and 5 minutes after the test. Blood samples were taken from a finger prick and analyzed using Lactate Scout device (SensLab $\mathrm{GmbH}$, Leipzig, Germany), values expressed in $\mathrm{mmol} / \mathrm{L}$.

Mean heart rate $\left(\mathrm{HR}_{\mathrm{m}}\right)$ and maximum heart rate $\left(\mathrm{HR}_{\max }\right)$ were monitored during all the lifesaving tests with the Suunto Team Pod (Suunto Oy, Vantaa, Finland), values expressed in beats per minute.

\section{STATISTICAL ANALYSIS}

All analyses were conducted using the SPSS 20 (IBM, USA) statistical package for Mac. The results are presented as mean and standard deviation (SD). Firstly, Shapiro-Wilk test for normality was used. Nonparametric procedures were utilized when normality could not be 
assumed: Wilcoxon test for comparing lifesaving variables between NRE and FRT (time, physiology, and rescue distance) and Mann-Whitney $U$ test for comparing the same variables between sexes. When normality could be assumed, parametric analogous procedures were used: Student's t test for paired and unpaired groups, respectively. Repeated measures ANOVA was used in order to analyze the effect of 2 factors in CPR variables: 1 intra-group factor (test: baseline test vs CPR after NRE and FRT) and 1 inter-groups factor (sex). Additionally, Cohen's $d$ effect sizes for identified statistical differences were determined. When calculating effect sizes, pooled standard deviations were applied due to the absence of a control group. Effect sizes with values of $.2, .5$, and .8 were considered to represent small, medium, and large differences respectively. ${ }^{19}$ Pearson correlation coefficient was used to analyse associations between Borg Scale values and the objective variables. A $P<.05$ was considered significant.

\section{Results}

Twenty professional lifeguards (ten men and ten women) average age $21 \pm 2$ years old formed a convenience sample. Anthropometric variables are shown in Table 1.

The lifeguards' baseline values were acceptable, with a QCPR over 75\% (Table 2). However, quality decreased significantly more than 25\% after both rescues. Table 2 also shows that quality of chest compressions and ventilations worsened in both rescues, but decrease was higher without rescue equipment. Rescuers performed better in compression than in ventilation. For an analysis of the CCR, lifeguards performed compressions faster, but no significant differences were found.

Regarding the other studied variables (Table 3), TR represents the total time required to achieve the rescue. In all rescues the difference between NRE vs FRT were significant $(P<.001, \mathrm{ES}=1.41)$. This mean difference reflects that FRT improved the rescue by 103 seconds.
The data also show that men are faster than women in NRE (112 seconds of difference) and FRT (60 seconds of difference).

Analysis of the swimming trajectories shows that sea rescues do not follow a straight course. However, the use of equipment provides a better trajectory and thus shorter distance to swim. Data shows that lifeguards swam almost $20 \%$ less with rescue equipment, obtaining significant differences (Table 3 \& Figure 2). No differences were found between men and women.

Regarding the physical demand, an increase in blood lactate concentration was observed as the test progressed. After the rescue, lactate values were similar in the entire sample, including both NRE and FRT, $(P=.98$; $\mathrm{ES}=.01)$. However, in FRT, when comparing men and women, we found significantly higher LaR values in women $(P=.031 ; \mathrm{ES}=1.04)$, who took 1 minute more than men to complete the lifesaving test, a total of 190 seconds.

The maximum peak of lactic concentration was attained at the end of CPR (Figure 3), after rescue, especially for lifesaving with no rescue equipment with $1.9 \mathrm{mmol} / \mathrm{L}$ more than with fins and rescue tube. Concerning the RPE, no significant differences were found between NRE vs FRT $(P=.18)$ or between men and women with $P>.05$ in both rescues.

Mean heart rate responses for NRE were $126 \pm 11$ beats/min. This value was not significantly different from the mean value observed in the FRT. However, significant higher $\mathrm{HR}_{\max }$ was observed for NRE (204 \pm 2 beats/min) compared with FRT with a difference of 24 beats/min. No differences were found between men and women lifeguards $(P>.05)$.

Pearson coefficient indicates that there are no associations between perceived exertion scale and blood lactate concentrations neither after rescues nor resuscitations. We found significant association between RPE and time of rescue, $(\mathrm{r}=.567, P=.009)$ and distance $(\mathrm{r}=.654$, $P=.003)$ in NRE. Association between RPE and time of rescue was not significant when lifesaving was carried out with rescue aids.

Table 1. Descriptive statistic of data collection

\begin{tabular}{|c|c|c|c|c|c|c|c|c|c|c|}
\hline \multirow[b]{2}{*}{ Variables } & \multicolumn{3}{|c|}{ All $(n=20)$} & \multicolumn{3}{|c|}{ Male $(n=10)$} & \multicolumn{3}{|c|}{ Female $(n=10)$} & \multirow[b]{2}{*}{$P$} \\
\hline & Mean & $S D$ & $95 \% C I$ & Mean & $S D$ & $95 \% C I$ & Mean & $S D$ & $95 \% C I$ & \\
\hline Age (years) & 21 & 2 & $20-22$ & 22 & 2 & $21-23$ & 21 & 1 & $20-22$ & .17 \\
\hline Height $(\mathrm{cm})$ & 170 & 10 & $165-174$ & 178 & 6 & $173-183$ & 162 & 4 & $159-165$ & $<.001$ \\
\hline Weight (kg) & 69 & 12 & $64-75$ & 79 & 7 & $74-84$ & 59 & 6 & $55-63$ & $<.001$ \\
\hline BMI $\left(\mathrm{kg} / \mathrm{m}^{2}\right)$ & 23.8 & 2.2 & $22.7-24.8$ & 25.0 & 2.2 & $23.4-26.5$ & 22.6 & 1.7 & $21.4-23.8$ & .06 \\
\hline
\end{tabular}


Table 2. Cardiopulmonary variables by group and sex

\begin{tabular}{|c|c|c|c|c|c|c|c|c|c|c|c|c|}
\hline \multirow{2}{*}{\multicolumn{2}{|c|}{ Variables }} & \multicolumn{5}{|c|}{ All $(n=20)$} & \multicolumn{6}{|c|}{ Men $(n=10)$ vs Female $(n=10)$} \\
\hline & & $\overline{M e a n}$ & $S D$ & $(95 \% C I)$ & Anova $^{a}$ & $E S$ (range) & & Mean & $S D$ & $(95 \% C I)$ & $t_{\text {test }}^{c} P$ & $E S^{b}($ range $)$ \\
\hline \multirow[t]{6}{*}{ QCCp } & $B A S$ & 89 & 10 & $85-94$ & BAS vs NRE $=0.001$ & $1.31-0.11$ & $0^{n}$ & 90 & 7 & $85-95$ & 0.54 & 0.22 \\
\hline & & & & & & & 우 & 88 & 12 & $79-96$ & & \\
\hline & $N R E$ & 57 & 33 & $42-73$ & & & $0^{\prime \prime}$ & 60 & 36 & $34-85$ & 0.74 & 0.15 \\
\hline & & & & & BAS vs FRT $=0.01$ & & q & 55 & 32 & $32-78$ & & \\
\hline & $F R T$ & 61 & 35 & $45-77$ & & & $\sigma^{n}$ & 63 & 38 & $36-91$ & 0.82 & 0.11 \\
\hline & & & & & & & 우 & 59 & 34 & $35-83$ & & \\
\hline \multirow[t]{6}{*}{ QVp } & $B A S$ & 64 & 16 & $56-73$ & BAS vs $\mathrm{NRE}=0.001$ & $1.14-0.04$ & $0^{\prime \prime}$ & 60 & 21 & $49-74$ & 0.22 & 0.52 \\
\hline & & & & & & & \% & 69 & 13 & $60-76$ & & \\
\hline & $N R E$ & 41 & 23 & $30-51$ & & & $\sigma^{*}$ & 37 & 27 & $22-53$ & 0.53 & 0.31 \\
\hline & & & & & BAS vs FRT $=0.009$ & & q & 44 & 24 & $27-61$ & & \\
\hline & $F R T$ & 42 & 24 & $30-53$ & & & $\sigma^{\prime \prime}$ & 43 & 24 & $26-60$ & 0.77 & 0.56 \\
\hline & & & & & & & q & 59 & 34 & $21-59$ & & \\
\hline \multirow[t]{6}{*}{ QCPR } & $B A S$ & 77 & 10 & $7-81$ & BAS vs NRE and & $1.28-0.06$ & $0^{n}$ & 75 & 12 & $66-84$ & 0.44 & 0.31 \\
\hline & & & & & FRT $<0.001$ & & \% & 78 & 7 & $74-83$ & & \\
\hline & $N R E$ & 49 & 19 & $10-58$ & & & $\sigma^{*}$ & 49 & 25 & $31-67$ & 0.93 & 0 \\
\hline & & & & & & & q & 49 & 10 & $42-57$ & & \\
\hline & $F R T$ & 51 & 23 & $41-62$ & & & $\sigma^{\prime \prime}$ & 53 & 26 & $34-72$ & 0.74 & 0.17 \\
\hline & & & & & & & q & 49 & 20 & $36-64$ & & \\
\hline \multirow[t]{6}{*}{ CCR } & $B A S$ & 102 & 9 & $98-107$ & BAS vs NRE and & $0.45-0.28$ & $0^{\prime \prime}$ & 101 & 7 & 94-106 & 0.25 & 0.53 \\
\hline & & & & & FRT $>0.05$ & & \% & 105 & 9 & $98-112$ & & \\
\hline & $N R E$ & 105 & 12 & 99-111 & & & $\sigma^{*}$ & 106 & 14 & $94.1-118$ & 0.95 & 0 \\
\hline & & & & & & & q & 106 & 10 & $98-117$ & & \\
\hline & $F R T$ & 108 & 17 & $100-117$ & & & $\sigma^{\prime \prime}$ & 110 & 13 & $100-120$ & 0.71 & 0.18 \\
\hline & & & & & & & q & 107 & 21 & $91-123$ & & \\
\hline
\end{tabular}

BA, baseline CPR; ES, effect size.

${ }^{a}$ Anova; Bonferroni test (sig $<0.05$ ).

${ }^{b} t$ student.

${ }^{c} \mathrm{o}$, male; , , female.

\section{Discussion}

Our study shows that rescue equipment reduces lifesaving time and decreases swimming trajectory and physiologic exertion. As of today, there is no consensus concerning which rescue equipment should be used. ${ }^{12}$ Some studies even suggest that rescues are slowed down with the use of equipment that only provide flotation (torpedo buoy type), ${ }^{11}$ which may be why some lifeguards opt not to use it.

For short-distance rescues, the discussion focuses on the choice between getting into the water quickly without spending time putting on fins, or performing a safe rescue after spending time putting on fins. The key component for aquatic propulsion is the fins. A study by Barcala-Furelos et al. verified that rescue time reduction was attained when fins are used in combination with a rescue tube. ${ }^{10}$ This is supported by our results: lifeguards with fins and rescue tube finished the lifesaving 103 seconds earlier (33\%) and swam $80 \mathrm{~m}$ less. The currents and sea movement cause oscillating trajectories which require additional swimming and the use of fins improves the propulsive power and helps compensate tangential forces and keep the trajectory. This reduction of rescue time and distance could stop the drowning process and avoid hypoxic induced morbidity and mortality.

Why do people drown when trying to rescue someone? The physiological demands in a rescue can be very high, ${ }^{8}$ and there is little peer-reviewed research which describes the skill factors when swimming in the surf. ${ }^{20}$ Optimizing performance during rescue requires knowledge of the metabolic and physiological demands. In many areas, lifeguards work 3 to 6 months per year. Hence, it is possible that they may be less physically fit than professional swimmers, and they could underestimate the physiological demand of the rescue. Our results illustrate that the use of rescue aids minimizes the lactate peak after a postrescue CPR, although we found high levels of lactate after both tests. 
Table 3. Rescue response and physiological load variables by group and sex

\begin{tabular}{|c|c|c|c|c|c|c|c|c|c|c|c|c|}
\hline \multirow[b]{2}{*}{ Variables } & & \multicolumn{5}{|c|}{ All $(n=20)$} & \multicolumn{6}{|c|}{ Men $(n=10)$ vs Female $(n=10)$} \\
\hline & & $\overline{M e a n}$ & $S D$ & $(95 \%$ CI $)$ & $P^{a, b}$ & $\overline{E S \text { (range) }}$ & & Mean & $S D$ & $(95 \% C I)$ & $P^{b, c}$ & $\overline{E S \text { (range) }}$ \\
\hline \multicolumn{13}{|c|}{ Rescue performance } \\
\hline \multirow[t]{4}{*}{ Time $^{d}$} & $N R E$ & 319 & 127.0 & $260.0-378.9$ & $<.001^{a}$ & 1.41 & $0^{\prime \prime}$ & 264 & 40.3 & $234.7-292.3$ & $.019^{c}$ & 0.96 \\
\hline & & & & & & & Q & 376 & 159.6 & $261.3-489.6$ & & \\
\hline & $F R T$ & 216 & 57.2 & $189.6-243.2$ & & & $0^{n}$ & 190 & 32.0 & $165.1-214.3$ & $.002^{c}$ & 1.25 \\
\hline & & & & & & & Q & 250 & 64.2 & 199.9-300.1 & & \\
\hline \multirow[t]{5}{*}{ Distance $^{e}$} & NRE & 346 & 40.8 & $326.1-366.7$ & $<.001^{b}$ & 1.78 & $0^{\prime \prime}$ & 329 & 29.0 & $306.7-351.3$ & $.069^{b}$ & 0.47 \\
\hline & & & & & & & Q & 364 & 44.9 & $329.3-398.3$ & & \\
\hline & $F R T$ & 265 & 51.8 & 239.2-290.7 & & & $0^{n}$ & 263 & 47.8 & $226.3-299.7$ & $.879^{b}$ & 0.07 \\
\hline & & & & & & & O & 266 & 58.4 & $222.0-311.7$ & & \\
\hline & & & & $P h$ & siologica & load variab & & & & & & \\
\hline \multirow[t]{4}{*}{ Basal lactate ${ }^{f}$} & $N R E$ & 1.8 & 0.7 & $1.5-2.2$ & $.16^{b}$ & .33 & $0^{\prime \prime}$ & 2.0 & 1.4 & $1.3-2.7$ & $.542^{b}$ & 0.27 \\
\hline & & & & & & & Q & 1.8 & 0.6 & $1.3-2.3$ & & \\
\hline & $F R T$ & 1.6 & 0.6 & $1.4-1.9$ & & & $0^{n}$ & 1.6 & 0.5 & $1.2-2.0$ & $.642^{b}$ & 0.21 \\
\hline & & & & & & & Q & 1.7 & 0.7 & $1.2-2.2$ & & \\
\hline \multirow[t]{4}{*}{ Rescue lactate } & $N R E$ & 9.0 & 2.8 & $7.7-10.4$ & $.98^{b}$ & .01 & $0^{n}$ & 8.0 & 2.5 & $6.1-10.0$ & $.262^{b}$ & 0.51 \\
\hline & & & & & & & O & 9.5 & 3.1 & $7.6-11.9$ & & \\
\hline & $F R T$ & 9.1 & 1.5 & $8.3-9.8$ & & & $0^{n}$ & 8.1 & 1.2 & $7.2-9.1$ & $.031^{b}$ & 1.04 \\
\hline & & & & & & & Q & 9.6 & 1.4 & $8.5-10.6$ & & \\
\hline \multirow[t]{4}{*}{ CPR lactate } & $N R E$ & 12.6 & 1.8 & $11.7-13.4$ & $<.001^{b}$ & 1.08 & $0^{n}$ & 12.2 & 1.6 & $10.9-13.4$ & $.638^{b}$ & 0.21 \\
\hline & & & & & & & O & 12.7 & 2.1 & $11.1-14.3$ & & \\
\hline & $F R T$ & 10.7 & 2.2 & $9.7-11.8$ & & & $0^{n}$ & 9.9 & 2.0 & $8.4-11.5$ & $.280^{b}$ & 0.49 \\
\hline & & & & & & & Q & 11.3 & 2.6 & $9.3-13.2$ & & \\
\hline \multirow[t]{4}{*}{ Borg } & $N R E$ & 7 & 2 & $6-8$ & $.18^{b}$ & .31 & $0^{n}$ & 7 & 1.5 & $5.6-7.9$ & $.896^{b}$ & 0.05 \\
\hline & & & & & & & Q & 7 & 1.8 & $5.6-8.4$ & & \\
\hline & $F R T$ & 6 & 1 & $6-7$ & & & $0^{n}$ & 7 & 0.9 & $6.0-6.6$ & $.283^{b}$ & 0.49 \\
\hline & & & & & & & Q & 6 & 1.4 & $5.2-7.3$ & & \\
\hline \multirow[t]{4}{*}{ Max heart rate } & $N R E$ & 204 & 2 & 204-205 & $<.001^{b}$ & 2.83 & $0^{n}$ & 204 & 2 & $203-205$ & $.17^{b}$ & 0.32 \\
\hline & & & & & & & Q & 205 & 1 & 204-206 & & \\
\hline & $F R T$ & 180 & 10 & $175-185$ & & & $0^{n}$ & 179 & 11 & $170-187$ & $.57^{b}$ & 0.13 \\
\hline & & & & & & & Q & 182 & 8 & $175-188$ & & \\
\hline \multirow[t]{4}{*}{ Mean heart rate } & $N R E$ & 126 & 11 & $121-132$ & $.28^{b}$ & 0.21 & $0^{\prime \prime}$ & 125 & 1 & $116-135$ & $.41^{b}$ & 0.19 \\
\hline & & & & & & & Q & 130 & 2 & 119-137 & & \\
\hline & $F R T$ & 122 & 11 & $117-128$ & & & $0^{n}$ & 123 & 12 & $114-133$ & $.69^{b}$ & 0.09 \\
\hline & & & & & & & Q & 121 & 10 & $114-129$ & & \\
\hline
\end{tabular}

${ }^{a} \mathrm{Z}$ Wilcoxon.

${ }^{b} t$ student.

${ }^{c} U$ test, Mann-Whitney.

${ }^{d}$ Time measured in seconds.

${ }^{e}$ Distance measured in meters.

${ }^{f}$ Lactate in $\mathrm{mmol} / \mathrm{L}$.

Lactate blood concentration after CPR post lifesaving with rescue aids was significantly lower, but over 10 $\mathrm{mmol} / \mathrm{L}$. Contrary to expectations, these results suggest similar metabolic demands despite vast differences in time of rescue and distance between both lifesavings. Maximum heart rate analysis revealed significant peak intensity during NRE rescue, but comparisons between NRE and FRT showed similar $\mathrm{LaR}$ and $\mathrm{HR}_{\mathrm{m}}$. One possible explanation may be the efficient use of energy resources by the lifeguards, so that all available energy is used without compromising rescue performance independently of the duration of the event. Likewise, Prieto Saborit et al. did not find any large differences between lifeguards' blood lactate concentration after a rescue simulation with and without torpedo buoy (11.8 and $12.7 \mathrm{mmol} / \mathrm{L}$, respectively). ${ }^{11}$ Comparing men with women, blood lactate levels were higher in women after water rescue and after CPR, although differences were only significant in FRT for LaR. According to Kenney et $\mathrm{al}^{21}$ at the same submaximal exercise 


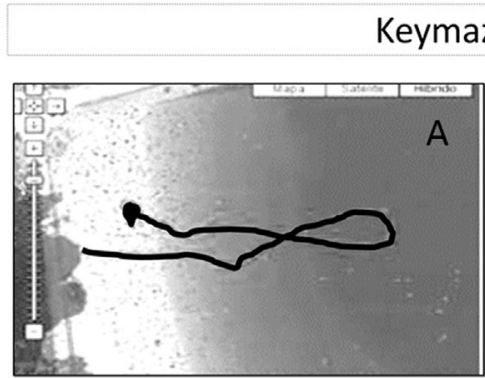

GPS plotted path without equipment $(A)$ and with equipment (B)

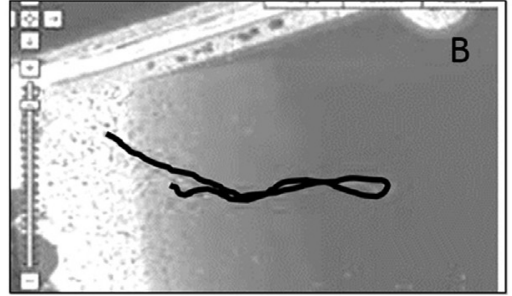

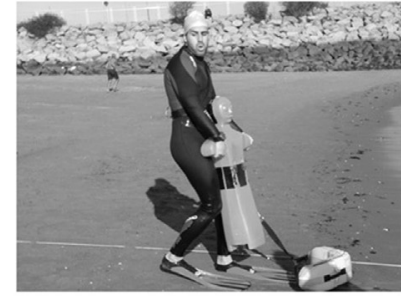

Lifeguard equipment

(Rescue tube and fins)

Figure 2. GPS water rescue record and lifeguard equipment.

intensity, women have higher heart rates and percentage of maximal oxygen uptake than men. Consequently, their blood lactate levels are also higher and lactate threshold is reached earlier. Significant differences in blood lactate levels after rescue with fins and rescue tube could be due to the dissimilarities of time spent by men and women. While men on average carried out the rescue in 3 minutes and 10 seconds, women spent on average 4 minutes and 10 seconds, and highest lactate levels in muscles and arterial blood are found in submaximal anaerobic efforts of 3 to 5 minutes. ${ }^{22}$

In addition to high blood lactate levels after lifesavings and CPR, high Borg scale values were registered regardless of the kind of rescue. It is true that lifeguards swam less time and distance with rescue equipment, but they described both tests as hard or really hard. Contrary to other studies, we did not find an association between lactate levels and perceived exertion. Scherr et al. revealed strong relationships between the Borg rating of perceived exertion and blood lactate in their study with more than 2000 participants. $^{23}$ In addition, associations between Borg scale and time, as well as distance, were significant as shown in other studies, ${ }^{24}$ which may be an important factor to measure training intensity. ${ }^{25}$

Another important variable in our study was the quality of CPR. The lifeguards in this research performed a baseline CPR within the quality standards. They reached a 77\% of QCPR, and quality resuscitation is considered when over $70 \%$ of compressions and ventilations are made correct. ${ }^{26}$ Similar results were reported in previous studies with the same protocol. ${ }^{10,15,27}$ In recent years, quality of compressions and hands-only CPR are gaining momentum, ${ }^{28}$ but in a

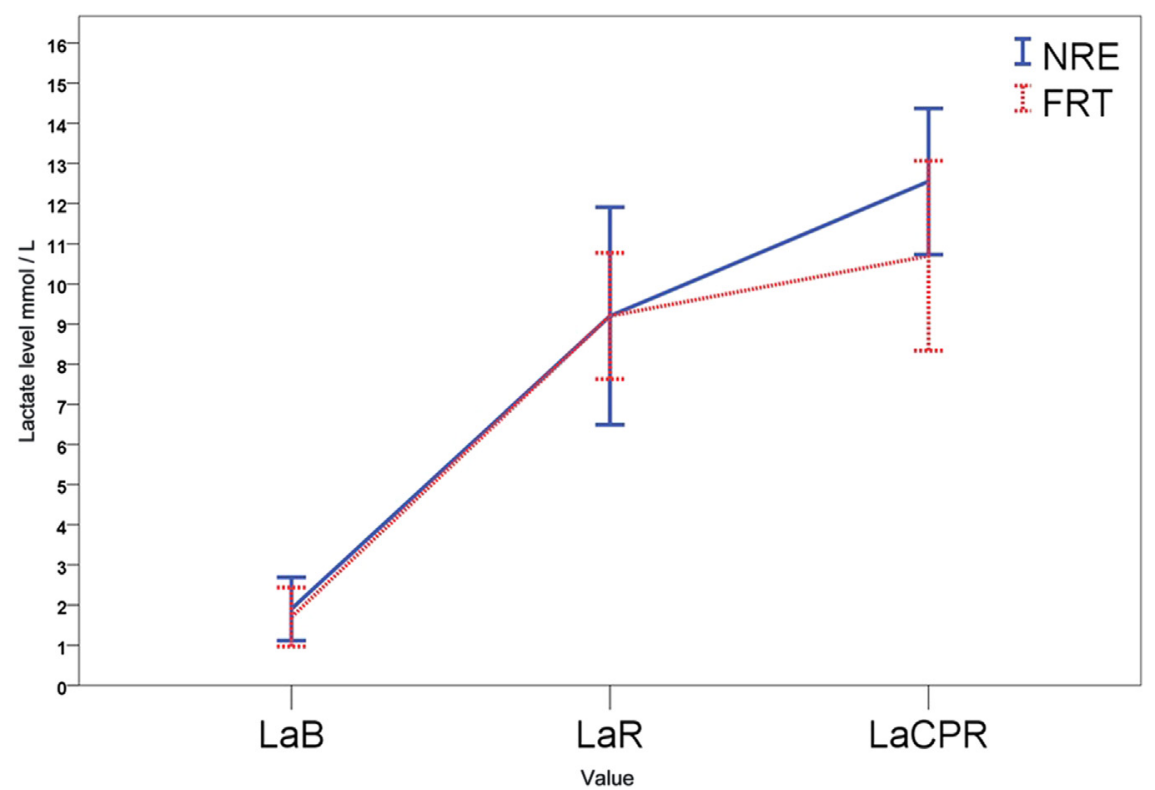

Figure 3. Lactate load axis. Values expressed in mmol/L. LaB, lactate level at the beginning of the rescue; LaR, lactate level at the end of the rescue; and LaCPR, lactate level after resuscitation. 
drowning event, CPR requires a combined great quality of compressions and ventilations to reverse hypoxia. ${ }^{2,28,29}$ Rescue breaths and airway management can be difficult. For this reason, more detailed instruction is required, especially for lifeguards. ${ }^{28}$

As prior studies have shown, resuscitation quality decreases dramatically after a water rescue. ${ }^{27,30}$ Lifeguards swam less distance and finished the test in less time when they used rescue equipment, but this was not sufficient to maintain CPR quality after water rescue. High blood lactate levels could be a reason for this finding, since lifeguards had to carry out the lifesavings with a maximum intensity. Despite reducing time, distance, and blood lactate levels after CPR, quality of resuscitation was significantly lower than basal conditions due to a progressive fall in gross efficiency as a consequence of acute fatigue. ${ }^{31}$ Therefore, a lifeguard should maintain a high aerobic capacity to lessen the accumulation of lactic acid and to reduce the influence of fatigue on resuscitation. ${ }^{32}$

\section{LIMITATIONS OF THE STUDY}

The fact that this study was carried out in an unstable environment presents multiple limitations, especially to standardize conditions at sea. However, it created a complex situation closer to real rescue conditions. To standardize the rescue, a simulation manikin was used. However, a human victim has other anthropometric and hydrodynamic conditions. Each lifeguard used their own fins, which is beneficial because they are already familiar with their use, but it is also a limitation, as the final efficiency may be affected by the material and size. It was not possible to carry out a test to assess the previous physical condition of the rescuers, although all the lifeguards in this study are professionals and must pass demanding physical tests every season to carry out their work at the beach. Other relevant limitations are the motivational factors or decisions made, which can only be evaluated in real incidents.

\section{Conclusions}

The use of fins and rescue tube provides a comprehensive benefit in an aquatic emergency. Rescue time as well as rescue distance were decreased. Lifeguards in this study had to simulate a real emergency situation developing high-effort intensities, regardless of the use or nonuse of rescue equipment, and we found that lactate peak was smaller using FRT after CPR on the shore.

We recommend that after a water rescue, CPR is performed by a rested lifeguard, in particular in light of the data and results obtained. Lifeguards should train in resuscitation skills after simulated water rescues to minimize the effect of physical fatigue. Further studies in this field may help to improve the quality of CPR post lifesaving.

Acknowledgment: The authors thank the lifeguards involved in this trial.

Author Contributions: Study concept and design: (AB-C), (CA-G); acquisition of the data: (J-CV), (CA-G), (JP-A), (AB-C), (SL-G), (RB-F), (MM-C); analysis of the data: (ER-E); drafting of the manuscript: (CA-G), (RB-F), (SL-G), (MM-C); critical revision of the manuscript: (RB-F), (SL-G), (ER-E), (MM-C), (CA-G); and approval of final manuscript: (J-CV), (CA-G), (JP-A), (AB-C), (SL-G), (RB-F), (MM-C), (ER-E).

Financial/Material Support: None.

Disclosures: None.

\section{References}

1. Australian Policy Online. Global report on drowning: preventing a leading killer. 2014. Available at: http:// apo.org.au/node/42350. Accessed.

2. Szpilman D, Bierens JJ, Handley AJ, Orlowski JP. Drowning. N Engl J Med. 2012;366:2102-2110.

3. Mott TF, Latimer KM. Prevention and treatment of drowning. Am Fam Physician. 2016;93:576-582.

4. Peden AE, Franklin RC, Leggat PA. Alcohol and its contributory role in fatal drowning in Australian rivers, 2002-2012. Accid Anal Prev. 2017;98:259-265.

5. World Health Organization. Global report on drowning. Geneva: World Health Organization; 2014.

6. Moran K. Will they sink or swim? New Zealand youth water safety knowledge and skills. Int J Aquatic Res Ed. 2008;2:114-127.

7. Bierens JJ, Lunetta P, Tipton M, Warner DS. Physiology of drowning: a review. Physiology (Bethesda). 2016;31: 147-166.

8. Reilly T, Wooler A, Tipton M. Occupational fitness standards for beach lifeguards. Phase 1: the physiological demands of beach lifeguarding. Оссир Med. 2006;56: $6-11$.

9. Attard A, Brander RW, Shaw WS. Rescues conducted by surfers on Australian beaches. Accid Anal Prev. 2015;82: 70-78.

10. Barcala-Furelos R, Abelairas-Gomez C, Romo-Perez V, Palacios-Aguilar J. Influence of automatic compression device and water rescue equipment in quality lifesaving and cardiopulmonary resuscitation. Hong Kong J Emerg Med. 2014;21:291-299.

11. Prieto Saborit JA, del Valle Soto M, González Díez V, et al. Physiological response of beach lifeguards in a rescue simulation with surf. Ergonomics. 2010;53:11401150 .

12. United States Lifeguard Standards Coalition. United States lifeguard standards: an evidence-based review and report by the United States Lifeguard Standards Coalition. Int J Aquatic Res Ed. 2011;5:61-129.

13. Szpilman D, Webber J, Quan J, et al. Creating a drowning chain of survival. Resuscitation. 2014;85:1149-1152. 
14. Koster RW, Baubin MA, Bossaert LL, et al. European Resuscitation Council Guidelines for Resuscitation 2010. Section 2. Adult basic life support and use of automated external defibrillators. Resuscitation. 2010;81: 1277-1292.

15. Barcala-Furelos R, Abelairas-Gomez C, Romo-Perez V, Palacios-Aguilar J. Effect of physical fatigue on the quality CPR: a water rescue study of lifeguards: physical fatigue and quality CPR in a water rescue. Am J Emerg Med. 2013;31:473-477.

16. Morgan D, Ozanne-Smith J. Surf lifeguard rescues. Wilderness Environ Med. 2013;24:285-290.

17. GPS Geonaute Keymaze 700. Manuel d'utilisation. Available at: http://customercare.geonaute.com/hc/fr/arti cle_attachments/202116232/55484_KEYMAZE_QUE CHUA_500_55485_KEYMAZE_KALENJI_700_FR.pdf. Accessed June 2017.

18. Borg GA. Psychophysical bases of perceived exertion. / Les bases psychophysiques de la perception de l' effort. Med Sci Sports Exerc. 1982;14:377-381.

19. Cohen J. Statistical Power Analysis for the Behavioural Sciences. 2nd ed. Hillsdale, NJ: Lawrence Erlbaum; 1988.

20. Tipton M, Byatt A. Lifeguard swimming performance in surf. In: Tipton M, Wooler A, eds. The Science of Beach Lifeguarding. Boca Raton, FL: CRC Press; 2016:195-202.

21. Kenney WL, Wilmore J, Costill D. Physiology of Sport and Exercise. 5th ed. Champaign, IL: Human Kinetics; 2012.

22. Platonov VN. Teoría general del entrenamiento deportivo Barcelona: Paidotribo; 2001.

23. Sherr J, Wolfarth B, Christle JW, Pressler A, Wagenpfeil S, Halle M. Associations between Borg's rating of perceived exertion and physiological measures of exercise intensity. Eur J Appl Physiol. 2013;113:147-155.
24. Eston R. Use of ratings of perceived exertion in sports. Int J Sports Physiol Perform. 2012;7:175-182.

25. Seiler $\mathrm{S}$. What is best practice for training intensity and duration distribution in endurance athletes? Int J Sports Physiol Perform. 2010;5:276-291.

26. Perkins GD, Colquhoun M, Simons R. Training manikins. In: Colquhoun MC, Handley AJ, Evans TR, eds. ABC of Resuscitation. 5th ed. London, UK: BMJ books; 2004: 97-101.

27. Abelairas-Gómez C, Romo-Pérez V, Barcala-Furelos R, Palacios-Aguilar J. Efecto de la fatiga física del socorrista en los primeros minutos de la reanimación cardiopulmonar posrescate acuático. Emergencias. 2013;25:184-190.

28. Schmidt A, Szpilman D, Berg I, Sempsrott J, Morgan P. A call for the proper action on drowning resuscitation. Resuscitation. 2016;105:e9-e10.

29. Soar J, Perkins GD, Abbas G, et al. European Resuscitation Council Guidelines for Resuscitation 2010 Section 8. Cardiac arrest in special circumstances: electrolyte abnormalities, poisoning, drowning, accidental hypothermia, hyperthermia, asthma, anaphylaxis, cardiac surgery, trauma, pregnancy, electrocution. Resuscitation. 2010;81: 1400-1433.

30. Claesson A, Karlsson T, Thorén A, Herlitz J. Delay and performance of cardiopulmonary resuscitation in surf lifeguards after simulated cardiac arrest due to drowning. Am J Emerg Med. 2011;29:1044-1050.

31. Grassi B, Rossiter HB, Zoladz JA. Skeletal muscle fatigue and decreased efficiency: two sides of the same coin? Exerc Sport Sci Rev. 2015;43:75-83.

32. Reilly T, Tipton M. Occupational fitness and strength standards for beach lifeguarding. In: Tipton M, Wooler A, eds. The Science of Beach Lifeguarding Boca Raton, FL: CRC Press; 2016:221-232. 